\title{
Experimental study of dense pyroclastic density currents using sustained gas-fluidized granular flows
}

Pete J. Rowley $1, *$

Email pete.rowley@gmail.com

Olivier Roche 1

Timothy H. Druitt 1

Ray Cas 1

1 Université Blaise Pascal, Clermont-Ferrand, France

\section{Abstract}

We present the results of laboratory experiments investigating the behaviour of relatively long-lived dense granular flows on horizontal slope in which we simulate long-lived high pore pressure through the continuous injection of gas through the flow base. Sustained (>30 s) supply of fine $(75 \pm 15 \mu \mathrm{m})$ particles from a hopper simulates pyroclastic density current formation fed by long-lived fountain collapse, which is inferred to deposit very large volume and often widespread ignimbrites. Material is released at initial particle concentrations of $\sim 3$ to $45 \%$, and dense flows form readily at the impingement surface even at lowest concentrations due to particle accumulation. When gas is supplied at the flow base at rates below the minimum fluidization velocity (i.e. aeration), three flow phases and regimes are identified; (i) an initial dilute spray travelling at $1-2 \mathrm{~m} \mathrm{~s}^{-1}$, then (ii) a dense gas-particle flow travelling at $0.5-1 \mathrm{~m} \mathrm{~s}^{-1}$, which comes to rest at a distance linearly dependent on the initial mass flux and finally (iii) dense flow pulses that aggrade a deposit much thicker than the phase 2 flow itself. The flow front velocity in phase 2 has a square-root dependence on mass flux, while the propagation speed of phase 3 deposit front has a linear relationship with it. The mass of the charge released has no significant control on either flow velocity or runout. In contrast, fully fluidized flows with gas supply equal to the minimum fluidization velocity 
remain within phase 2 for their duration, no deposit forms, and the material exits the flume, precluding quantification of the effect of mass flux on runout. During phase 3 in aerated conditions, high-frequency unsteadiness leads to flow waxing and waning, creating deposit architectures that exhibit features observed in many ignimbrites, including localised progradational and retrogradational phases of deposition and erosive contacts.

\section{Keywords}

Fluidization

Pyroclastic flow

Density current

Pore pressure

Sustained supply

Experiments

Editorial responsibility: V. Manville

\section{Electronic supplementary material}

The online version of this article (doi: 10.1007/s00445-014-0855-1 ) contains supplementary material, which is available to authorized users.

\section{Introduction}

Pyroclastic density currents (PDCs) are particle-laden flows produced by the gravitational collapse of lava domes, lateral explosion (cf. Mount St. Helens) or by the fallback of eruption columns (Druitt 1998; Branney and Kokelaar 2002). They have runouts ranging from hundreds of metres to more than a hundred of kilometres (Lube et al. 2007; Cas et al. 2011), are able to surmount topographic obstacles (Loughlin et al. 2002) and contain a wide range of particle sizes and densities. Density currents propagate across the ground due to a combination of initial momentum and density contrast with the atmosphere, with density contrast usually acting as the main driving force (Middleton 1966; Simpson 1999; Esposti-Ongaro et al. 2011). PDCs exhibit a spectrum of flow behaviours and bulk densities, from dense granular flows (commonly termed the basal avalanche) with over-riding dilute ash clouds, to dilute, turbulent flows with bedload layers (e.g. Dufek and Bergantz 2007a, b; Dufek et al. 2009; Andrews and Manga 2011, 
Pyroclastic density currents are hazardous to populations living on and around active volcanoes, and the understanding of their dynamics is vital to both improved hazard assessment and better interpretation of their deposits. The ability of some PDCs to traverse topographic obstacles and achieve long runouts even on subhorizontal slopes (e.g. Cas et al. 2011) makes them a particular focus of hazard mitigation planning. The high mobility of the dense basal avalanche of some PDCs is attributed to the combined effects of (i) low intergranular friction caused by excess (i.e. above atmospheric pressure) gas pore pressures and consequent fluidization effects (Sparks 1976; Wilson 1980; Druitt et al. 2007), and (ii) long-lived high pore pressure favoured by slow pore diffusion due to the low permeability of the particulate material, dominated by very fine ash (Druitt et al. 2007; Roche et al. 2010; Roche 2012). Possible origins of excess gas pore pressures caused by gas-particle differential motion in dense PDCs include (hindered) settling of particles from an initially expanded state (Girolami et al. 2008), exsolution of gas from juvenile clasts (Wilson 1980), ingestion of air at the flow front and sides (Bareschino et al. 2008) and air escape from a rough substrate (Chédeville and Roche 2014).

Fluidization is a process with many industrial applications in the transport and storage of granular materials (Fan and Zhu 2005; Rhodes 2008; Savage and Oger 2013). By injecting gas vertically into a granular bed, a condition can be reached whereby the drag exerted by the gas counterbalances the weight of the particles, at which point intergranular friction is lost and the bed behaves in a liquid-like manner (Geldart 1972; Gilbertson et al. 2008). The superficial vertical gas velocity, $U$ (equal to the gas volumetric flux divided by the surface area across which gas is supplied) at which this occurs is dependent on the material properties and is termed the minimum fluidization $\left(U_{m f}\right)$ velocity.

$$
U_{m f}=\frac{k_{m f}}{\mu} \times \rho_{m f} g
$$

where $k_{\mathrm{mf}}$ is the bed permeability, $\mu$ is the dynamic gas viscosity, $h_{\mathrm{mf}}$ is the bed height, $\rho_{\mathrm{mf}}$ is the bulk density of the mixture and $g$ is the gravitational acceleration. Beds of volcanic ash representative of the matrix material within pyroclastic flows have low permeabilities $\left(k_{m f} \sim 10^{-12}-10^{-11} \mathrm{~m}^{2}\right.$ and 
$U_{m f}$ as low as $\sim 1 \mathrm{~mm} \mathrm{~s}^{-1}$ ), and they expand homogeneously when fluidized at gas velocities above $U_{m f}$ until gas bubbles form at $U_{m b}>U_{m f}$ (Druitt et al. 2007), showing that they belong to group A of Geldart's classification (Geldart 1973). Shear in a moving dense particulate flow moreover favours homogeneous fluidization-generated expansion by breaking down any bubbles (Nezzal et al. 1998; Druitt et al. 2004). A bed in which $0<U<U_{m f}$ is termed aerated and one in which $U \geq U_{m f}$ is termed fluidized. When gas is no longer provided to fluidized beds of group A particles, negligible internal friction can be maintained for a while as excess pore pressure decreases slowly by diffusion on a typical time scale of:

$$
t_{d} \propto h_{m f}^{2} / D
$$

where $D$ is the diffusion coefficient of the gas in the granular mixture (Iverson and LaHusen 1989; Druitt et al. 2007; Roche 2012).

In experiments on fluidized granular flows applied to dense PDCs, the use of group A particles is required to ensure dynamic similarity with the natural system as discussed by Roche (2012). Previous experimental studies on dense PDCs focussed on releasing almost instantaneously a volume of initially fluidized group A powder onto a horizontal surface (Roche et al. 2004; Girolami et al. 2008). One problem is that the similar material mean grain size, and hence permeability and diffusion coefficient, in both experiments and PDCs leads to pore pressure diffusion timescales that are significantly different, since the experimental flows are 1-3 orders of magnitude thinner than the natural ones (Hoblitt 1986; Palladino and Valentine 1995; Dellino et al. 2007). As such, pore pressure is lost more rapidly in fluidized experimental flows than in natural PDCs. Experimental flows come to a relatively rapid halt and form relatively much shorter deposits than those of their natural counterparts. One way to overcome the relatively rapid decrease of pore pressure in experimental flows is to sustain fluidization through a continuous air supply at the flow base (Eames and Gilbertson 2000; Savage and Oger 2013). We have developed a methodology for sustaining fluidization during flow in order to better model the emplacement of ignimbrite-forming PDCs with long-lived high pore pressure. By supplying a continuous gas flux through the flow substrate, we can simulate the behaviours of natural flows with long diffusion timescales.

This paper reports the results of experiments on sustained fluidized dense 
granular flows (approaching maximum particle concentration) in which the material supply duration is equal to or greater than the time taken for the flow front to reach its distal limit. We explore how the mass of particles, the mass flux and the degree of fluidization affect the speed, runout and depositional behaviour of the flows. These experiments differ from previous studies on dam-break granular flows produced by instantaneous gravitational fluidized column collapse and with no air supply from below.

$\mathrm{AQ1}$

\section{Methods and materials}

The experimental apparatus is shown in Fig. 1. A 35-kg capacity hopper supplied the particles to a 3.5-m-long horizontal flume through a lock-gate release mechanism, with a variable aperture to control the mass flux. The particles dropped $60 \mathrm{~cm}$ onto an impingement plate consisting of a porous plate inclined at $10^{\circ}$, then propagated into the horizontal channel section, which also had a porous base. The drop height was selected through testing in order to allow the particles to approach their terminal velocity when falling as clusters (Nakashima et al. 2009). Air was supplied through both the impingement plate and the channel base at the calculated velocity required to provide a given degree of gas fluidization. The flume was $10 \mathrm{~cm}$ wide, with vertical Perspex sidewalls $30 \mathrm{~cm}$ tall. These dimensions were selected to ensure that the flume was wide enough to minimise sidewall effects (Girolami et al. 2008) without increasing the necessary particle volumes to impractical values. We refer to the volume above the impingement plate as the 'reservoir', as it is analogous to the reservoir in dam-break experiments (e.g. Roche et al. 2010). All experiments were recorded using high-speed video at 500 frames per second with a horizontal resolution of 1,024 pixels, enabling frame-by-frame analysis to record front propagation, as well as to observe qualitative details of the flow and deposit formation. By filling the hopper with alternating dyed and undyed particles, it was possible to analyse the behaviour of flow and deposition in detail. The particles exited the hopper in such a way as to provide continuous variation in deposit colour (Fig. 2), providing a high-resolution method of imaging the internal flow and deposit structure. All runout measurements are expressed as distance from the entry into the channel, and times are given relative to the instant at which the flow first enters the channel from the reservoir.

Fig. 1 
Scaled longitudinal section of the experimental apparatus. The flume exit (right) and top are open to prevent air recirculation or reflection artifacts

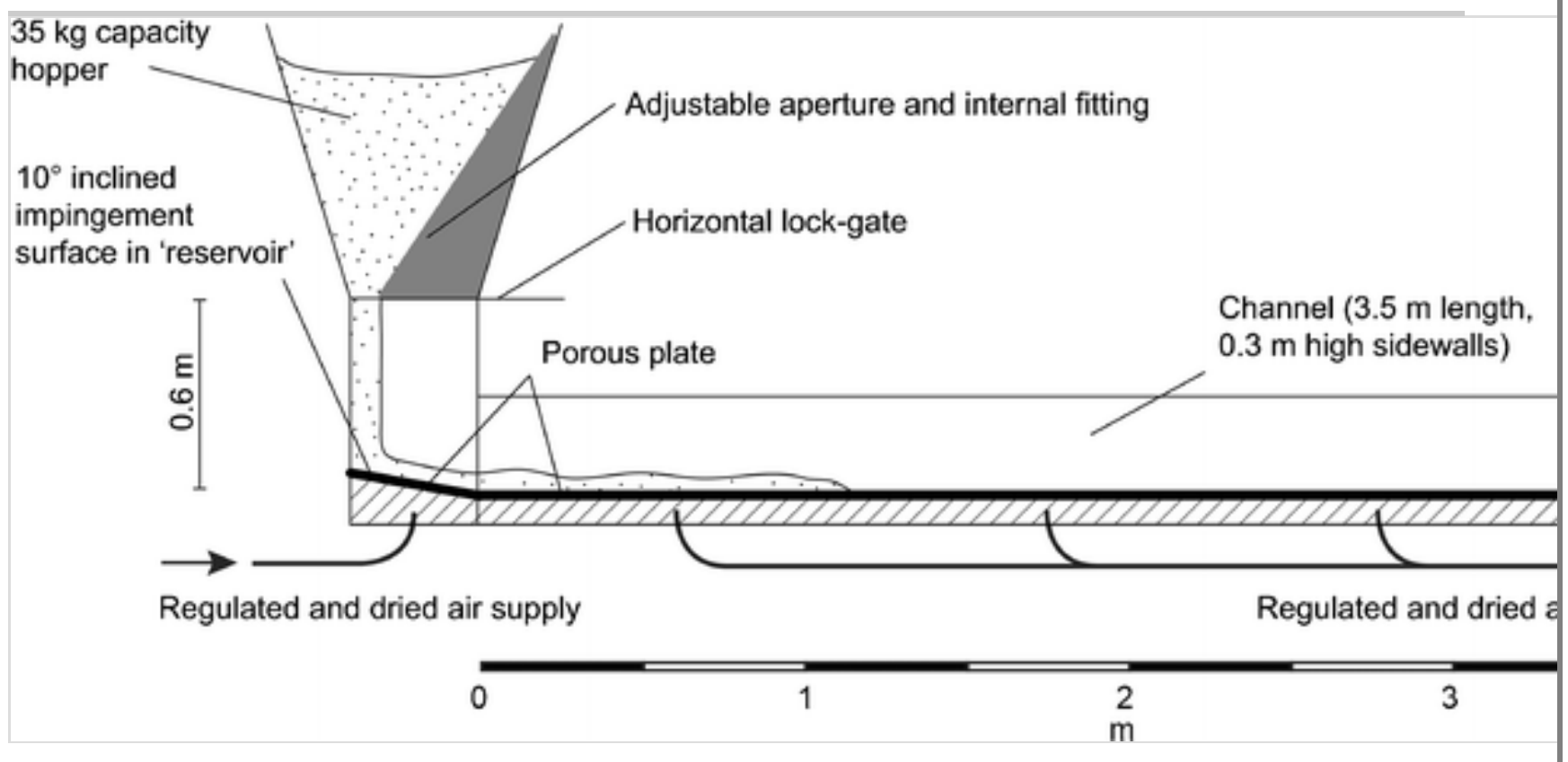

\section{Fig. 2}

Sequence of three photographs showing emptying of the hopper using a 3layer charge. Note the temporal variation in the proportion of different coloured ballotini being supplied

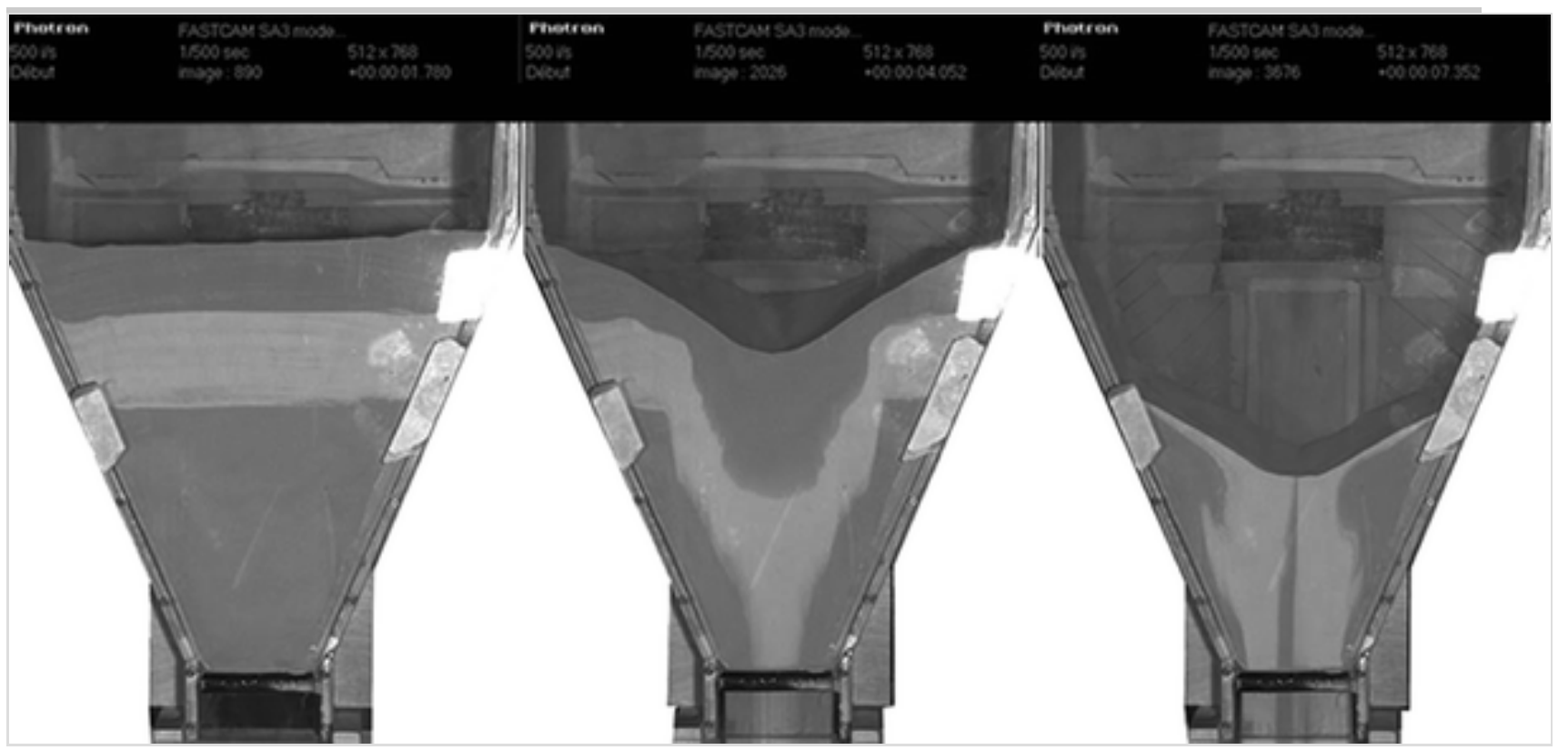

The experiments were carried out using glass ballotini with a grain size of 75 $\pm 15 \mu \mathrm{m}$ and repose angle of $27^{\circ}$, identical to those of Roche et al. (2004). These particles are fine enough to exhibit Geldart group A properties (significant expansion prior to the onset of bubbling) and long pore pressure 
diffusion timescales, but are coarse enough to experience negligible cohesion (Schellart 2000; Gilbertson and Eames 2003). $U_{m f}$ for the particles has been determined previously as $0.83 \mathrm{~cm} \mathrm{~s}^{-1}$ and $U_{m b}$ as $1.6 \mathrm{~cm} \mathrm{~s}^{-1}$ (i.e. about $2 U_{m f}$, Roche et al. 2006).

The three variables in the experiments are (i) the total mass of particles leaving the reservoir and entering the channel, (ii) the mass flux of particles leaving the reservoir and (iii) the gas supply velocity through the base of the flume. The mass of particles ranged from 10 to $25 \mathrm{~kg}$. The mass flux was calculated by dividing the total mass by the time it took for the reservoir to empty. Mass fluxes of 0.8 to $65 \mathrm{~kg} \mathrm{~s}^{-1}$ were achieved through a variable aperture at the base of the hopper of 1 to $20 \mathrm{~cm}$ width, respectively. The experiments were conducted with the same fluidization conditions simultaneously in the reservoir and channel: non-fluidized $(U=0)$, aerated $\left(U=0.5 U_{m f}\right)$ or fluidized $\left(U=U_{m f}\right)$.

\section{Results}

\section{Calibration of the particle supply}

Visual inspection of videos of the falling material in the reservoir showed that it was quite heterogeneous in both the early and latter stages (as the ballotini were first released and then as the hopper finally emptied), consisting of clumps and curtains of particles of different concentrations. This overprints a very rapid $(<0.3 \mathrm{~s})$ waxing as the first material is supplied and waning as the hopper empties. Arrival of heterogeneities on the impingement plate caused splashing and a high-frequency unsteadiness in particle supply that was then transmitted to the horizontal flows, as described below. We calibrated the time-variation of mass flux for different aperture sizes of the hopper by placing a balance on the floor of the reservoir and recording the force exerted on the balance as a function of time $(0.04 \mathrm{~s}$ intervals and $0.1 \mathrm{~g}$ precision). The results (Fig. $3 \mathrm{a}$ ) show that the timeaveraged flux was approximately constant, but increased slightly as the reservoir emptied. We concluded that our hopper supplied particles at an approximately constant flux when averaged over periods greater than $0.12 \mathrm{~s}$ upon which the higher frequency, splash-generated unsteadiness was superimposed. The observed velocity of impact on the impingement plate was approximately $3.4 \mathrm{~m} \mathrm{~s}^{-1}$, which is equal to the freefall velocity $\sqrt{ }(2 \mathrm{gh})$, where $\mathrm{h}$ is the $60 \mathrm{~cm}$ drop height. 
Fig. 3

a Plot demonstrating steady supply of a $15 \mathrm{~kg}$ charge from the hopper, measured using a data logging balance placed $60 \mathrm{~cm}$ below the mouth of the hopper at an aperture of $5 \mathrm{~cm}$, providing a calculated mean mass flux of $\sim 5 \mathrm{~kg} \mathrm{~s}^{-1}$. b Calculated particle concentrations for varying mass flux conditions, using high-speed footage to estimate particle fall rate, assuming constant mass flux and that the cross-sectional area of impingement is the same as the hopper aperture. Fit curve is applied demonstrating concentration has a power law dependence on mass flux. c Reproducibility of flow propagation for a $15 \mathrm{~kg}$ charge supplied at $5 \mathrm{~kg} \mathrm{~s}^{-1}$, fluidized at $U=U_{m f}$. The flows exit the video frame at approximately $2.3 \mathrm{~s}$. All distances are measured from the start of the channel. d Flow speed derived from (b), with individual flows plotted in grey, and an average curve plotted in black. Of note is the rapid deceleration on entering the channel, followed by a pulsing unsteady flow head
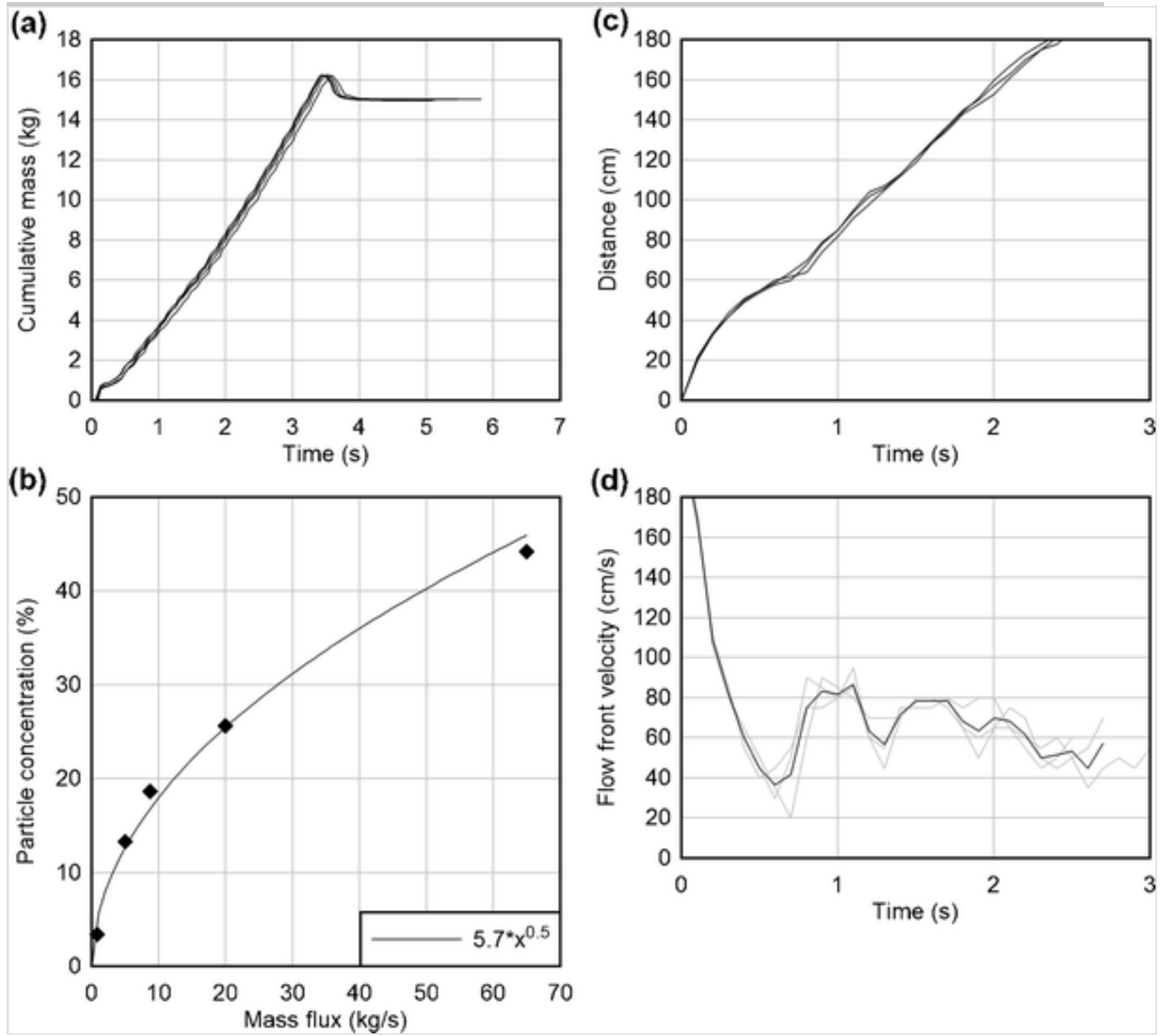
We also estimated the time-averaged concentration of particles, $C$, impacting the impingement plate under conditions of different mass fluxes from the relationship.

$$
C=\frac{\dot{M} t}{d A \rho_{s}},
$$

where

$\dot{M}$ is the measured mean mass flux, $d$ is the distance particles fall during the period between frames $t, \rho_{S}$ is the particle density $\left(2,500 \mathrm{~kg} \mathrm{~m}^{-3}\right)$ and $A$ is the cross-sectional area of the aperture. The results are presented in Fig. $3 \mathrm{~b}$ and show that higher mass fluxes generated higher particle concentrations upon impingement. Mass fluxes of $<1 \mathrm{~kg} \mathrm{~s}^{-1}$ are calculated to generate timeaveraged concentrations as small as 3-4\%, which must have then densified significantly before forming the dense flows that propagated through the channel as described hereafter. In contrast, the higher mass flux experiments $\left(65 \mathrm{~kg} \mathrm{~s}^{-1}\right)$ produced concentrations on impingement of approximately $45 \%$ (note that maximum particle concentration of randomly packed spheres approaches 64 \%; (Bernal and Mason 1960; Song et al. 2008).

A series of initial tests, in which we repeated measurements under the same conditions, showed that our experimental results were highly reproducible. This is true of the particle mass flux exiting the reservoir (Fig. 3a), distancetime plots for the flow fronts (Fig. 3c) and flow front velocity, obtained from the slope of the distance-time curves (Fig. 3d). Comparing flow front position through time of the five repeated experiments in Fig. 3c, taking the flow front distance in each experiment at each $0.04 \mathrm{~s}$ step, for 80 time steps gives a mean correlation coefficient (Pearson's $r$ ) of 0.998 .

\section{Flow and deposition behaviour}

As the charge impinged on the reservoir base, it rapidly coalesced into a thin $(<20 \mathrm{~mm})$, dense flow. Even in low mass flux experiments, for which the calculated particle concentration prior to impingement was less than $20 \%$, the bulk of falling material had gravitationally collapsed to form a coherent dense flow within $0.1 \mathrm{~s}$. Flow behaviour and deposition varied according to the fluidization state of the particles. 
Non-fluidized and aerated flows

Emplacement of these flows took place in three overlapping phases (see representative video, Online Resource 1 ).

\section{Phase 1}

The force of the initial impact of particles on the base of the reservoir generated a violent spray of particles at high speed (up to $\sim 2 \mathrm{~m} \mathrm{~s}^{-1}$ ) down the channel. This spray formed a rapidly moving, millimeter-thin dense flow of particles, accompanied by an ephemeral dilute cloud of particles travelling down the flume above and in front of the denser flow, which rapidly formed a deposit just a few particle diameters in thickness with a diffuse front. The volume of particles involved in phase 1 was less than $1 \%$ of that involved in the subsequent main flow (phases 2 and 3). In most, but not all, experiments, the deposit from phase 1 was completely covered during phase 2. Phase 1 can be attributed in part to the generation of high pore pressure when the granular mass first impacted the impingement plate and was translated laterally. A similar phenomenon was observed in the 3D dambreak experiments of Roche et al. (2011) as a result of rapid pore pressure release at the base of a collapsing fluidized granular column.

\section{Phase 2}

The precursor flow was followed, and in most experiments overtaken, by a slower-moving $\left(0.1-1.0 \mathrm{~m} \mathrm{~s}^{-1}\right)$ dense granular flow. A key observation was that this flow formed even at lowest initial mass fluxes (i.e. lowest impingement concentrations) as particles accumulated at the impingement surface. The flow had thicknesses from a few particle diameters up to 10$20 \mathrm{~mm}$ (increasing with mass flux) and was highly unsteady due to the highfrequency unsteadiness in particle supply. It travelled down the flume as a series of pulsed waves; larger waves travelled faster than smaller ones and entrained any smaller waves that they over-rode. As each flow pulse travelled down the flume, it decreased in velocity and thickness. Arrival of each successive flow pulses at the flow front caused transient fluctuations in frontal velocity that are evident on a plot of flow front velocity versus distance (Fig. 3c).

Under aerated conditions, a granular jump (Boudet et al. 2007) appeared to form during phase 2 and phase 3 at the transition from the impingement plate to the flume, with a possible chute-and-pool structure (Schmincke et al. 
1973 ). The granular jump and chute and pool were not observed in fluidized flows and occurred too late in propagation to impact the flow front measurements.

\section{Phase 3}

Once the initial dense flow pulse had reached its distal limit, further supply then thickened the existing deposit and the distal limit moved at much slower rate, if at all. In non-fluidized cases, this growth occurred as a simple granular wedge, while in aerated flows the deposit formed through subhorizontal aggradation, with the runout of individual flow pulses inhibited by friction with the developing substrate. Non-fluidized phase 3 flows constantly prograded with a deposit front angle of between 15 and $20^{\circ}$, depending on the mass flux (high-mass fluxes producing lower angles). It is notable that these are below the angle of the rest of the ballotini particles $\left(27^{\circ}\right)$, likely as a result of flow momentum. Aerated phase 3 flows demonstrated more varied behaviour, including retrogradational deposit growth. The deposit surface from the aerated flows had more consistent angles, determined by the gas flow velocity (approximately $10^{\circ}$ for $0.5 U_{m f}$ aeration) and generated deposits that were thinner and longer than those from equivalent non-fluidized flows. Whether or not, the phase 3 flow overrode the distal extent of phase 1 and 2 deposits was controlled by the angle of the advancing slope and the total mass of the charge in the experiment, with large total masses and low angles favouring longer runouts. The fluidized flows travelled rapidly (up to $1 \mathrm{~m} \mathrm{~s}^{-1}$ ) down the length of the flume and exited at the distal end. Source-generated unsteadiness caused the frontal velocity to fluctuate, as in the non-fluidized and aerated flows. The thin precursor flow (phase 1) and the following main flow (phase 2) could not be distinguished. The fluidized flows $(5-100 \mathrm{~mm}$ in thickness) remained mobilised by gas support throughout their duration and can be considered non-depositional.

A typical example an aerated flow is shown in Fig. 4. Following rapid emplacement of the precursor flow (phase 1), the front of the initial dense flow reached its distal limit by $1.0 \mathrm{~s}$ (phase 2). The deposit then aggraded, with no further advance of the front (phase 3). During phase 3, (which lasted until shortly after the particle supply ceased at $2.0 \mathrm{~s}$ ), the successive flow pulses interacted with an increasingly steep and undulating depositional surface. Coloured beads within the final deposit revealed a millimeter-thick stratification with multiple, stacked progradational and retrogradational 
surfaces resulting from the waxing and waning of individual flow pulse. These surfaces occurred in localised groupings throughout the deposit, due to the flow waxing at one point in the flume, while simultaneously waning at another. The progradational surfaces (associated with waxing flow) also demonstrate erosive contacts, indicating that the flow was not completely depositional. A final flow pulse formed a drape over the entire deposit. As the deposit built, interaction with existing (and developing) topography became a strongly controlling factor in flow behaviour and the resulting deposit architecture.

\section{Fig. 4}

a-f High-speed video frames taken at $0.5 \mathrm{~s}$ intervals through the flow and deposition of a $10 \mathrm{~kg}$ multi-coloured charge supplied at $5 \mathrm{~kg} \mathrm{~s}^{-1}$ with a gas supply providing aeration at $0.5 U_{m f}$. Charge has been fully released by $2 \mathrm{~s}$, with the flow at complete rest by $3 \mathrm{~s}$. The chequerboard squares are $1 \mathrm{~cm}$ across for scale. Black lines indicate the deposit growth, highlighting the location of the top of the deposit at each 0.5 -s time interval. A video of this experiment is presented in Online Resource 1. g The final deposit, showing complex internal structure from the aggradational formation. $\mathbf{h}$ Final deposit in (g) with interpretation and deposit growth lines, highlighting a range of contacts including (red) progradational and (green) retrogradational phases of deposition. The progradational features frequently demonstrate erosive style contacts (e.g. the unit in the lower left of the deposit) 

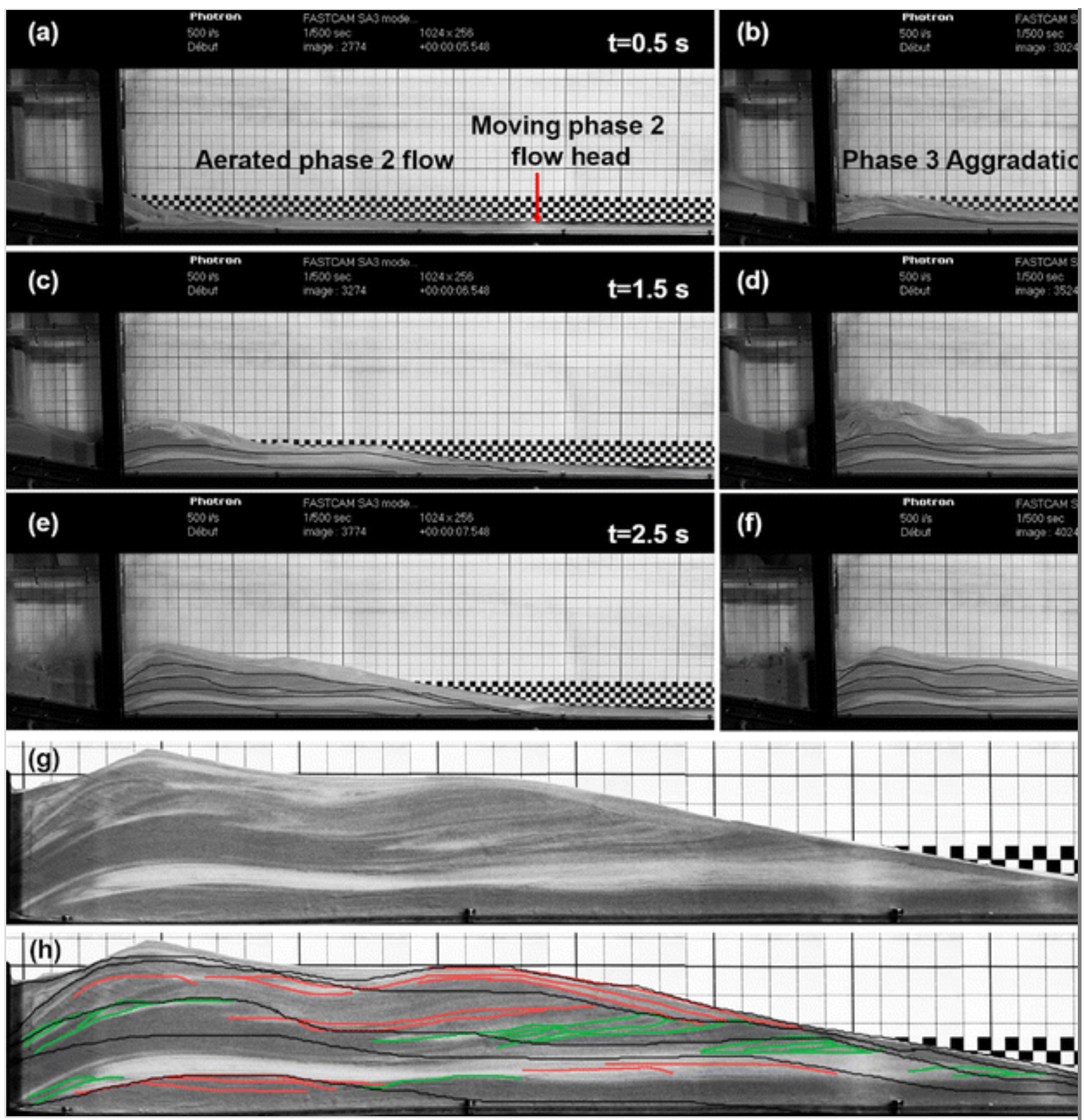

Characteristic times

The compound behaviours of these flow phases described above can be used in conjunction with material supply conditions to identify a number of characteristic times in each flow. We define $t_{\text {supply }}$ as the time at which the supply of material from the hopper ceases. This value ranged from 0.5 to $20 \mathrm{~s}$ depending on the charge mass and mass flux. $t_{\text {limit }}$ denotes the time at which the phase 2 flow comes to a halt, forming a distal deposit front which may or may not be overpassed by subsequent phase 3 deposition. A flow is said to be sustained when $t_{\text {limit }}<t_{\text {supply. }} . t_{\text {stop }}$ identifies the time at which all flow motion ceases. In the non-fluidized and aerated experiments, $t_{\text {stop }}$ is within $1 \mathrm{~s}$ of $t_{\text {supply }}$, while in the fluidized case this is undefined as the flow 
left the channel. These characteristic times are illustrated by labels for a $10 \mathrm{~kg}$ flow in Fig. 5a.

\section{Fig. 5}

a Effect of mass on distances of flow front propagation in non-fluidized conditions, at $5 \mathrm{~kg} \mathrm{~s}^{-1}$ mass flux, with the dotted line indicating phase $1 \mathrm{flow}$, the heavy line phase 2 and the fine line phase 3 . The points at which the flow front comes to a rest $\left(t_{\text {limit }}\right)$, the hopper empties $\left(t_{\text {supply }}\right)$ and the flow comes to a complete rest $\left(t_{\text {stop }}\right)$ are indicated for the $10 \mathrm{~kg}$ charge. All three lines end at the relevant $t_{\text {stop }}$. Note that phase 3 starts after $\sim 0.3 \mathrm{~s}$, but only grows the deposit sufficiently to overcome the preexisting phase 2 deposit front after $\sim 1.7$ s. Phase 3 propagation between channel entry and over-riding of the distal extent of phase 2 is not plotted. The flows are remarkably similar for the first $2.7 \mathrm{~s}$, with a very weak inverse relationship between charge mass and propagation speed. Final runout is strongly determined by the volume of material due to the wedge-like growth in these non-fluidized conditions. b Dependence of runout on charge mass in both non-fluidized $(U=0)$ and aerated $\left(\begin{array}{ll}0.5 U_{m f}\end{array}\right)$ conditions. Fits are achieved by determining the intercept using the measured angle of repose with the reservoir geometry and assuming growth at the measured angle of repose that is $17^{\circ}$ in the non-fluidized experiments and $9^{\circ}$ in the aerated cases. The fit lines assume that the runout requires a wedge of material at the angle of repose to first grow to the extent of the reservoir before the flow can enter the channel (runout $=0$ ) 

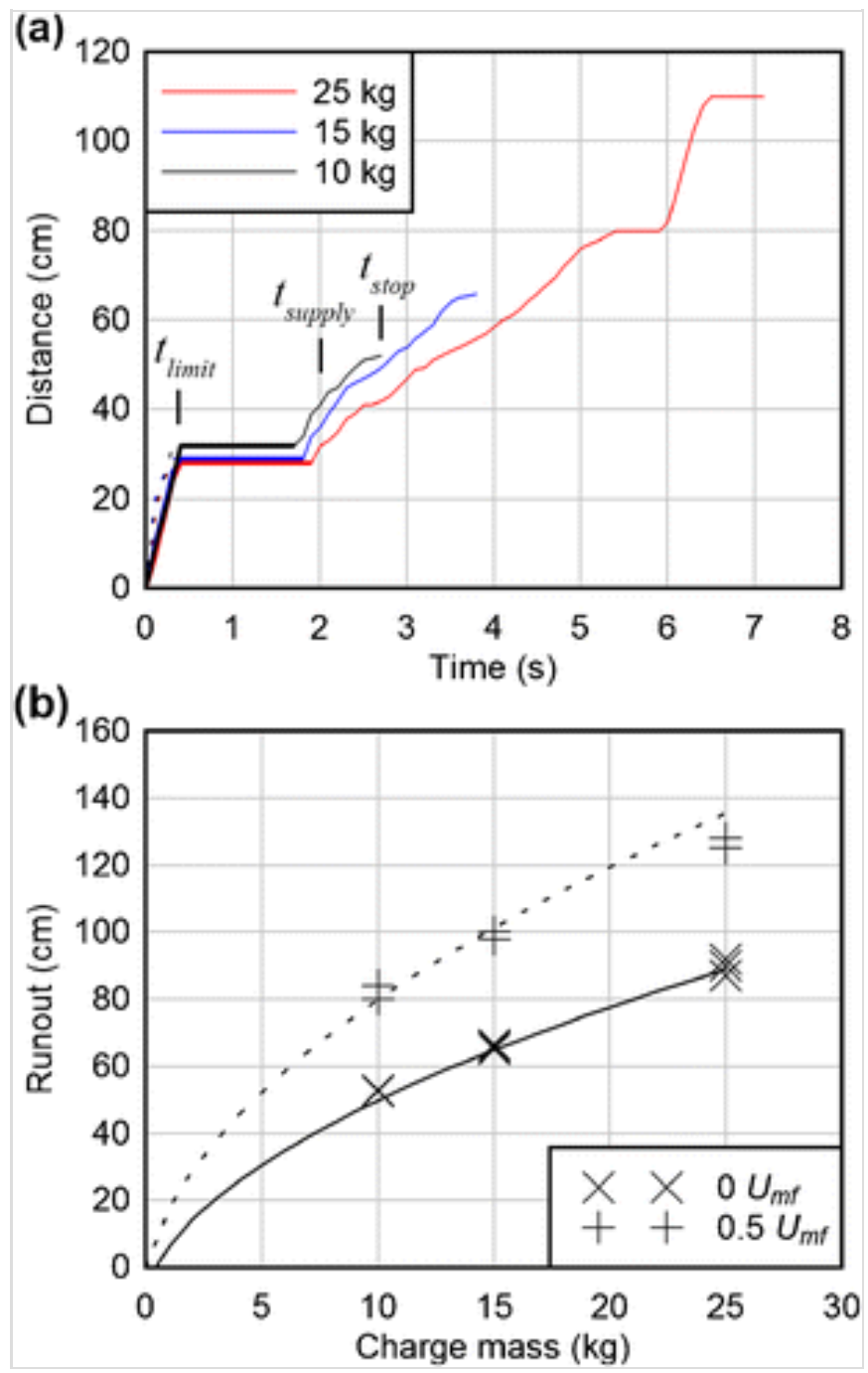

\section{Effect of mass released}

We investigated the effect of total particle mass released on flow behaviour by carrying out experiments with non-fluidized flows at masses of 10, 15 and $25 \mathrm{~kg}$, and constant mass flux $\left(5 \mathrm{~kg} \mathrm{~s}^{-1}\right.$ - similar results were achieved in experiments with mass flux between 0.8 and $65 \mathrm{~kg} \mathrm{~s}^{-1}$ ). At a fixed mass flux, increasing the total mass (and therefore volume) increased flow runout (Fig. 5a). The flow front velocities, on the other hand (slope on Fig. 5a), were much less dependent on total mass; the very weak inverse dependence could be due to higher initial material compaction (and development of stress arches at the hopper mouth) as mass increased (Walton and Braun 1986; GDR MiDi 2004; Carlevaro and Pugnaloni 2012), leading to a very subtly reduced initial mass flux (see below). Aerated flows travelled further than non-fluidized flows of a given mass (and mass flux), but the curve of a plot of runout versus mass is similar to that for the non-fluidized case (Fig. 5b).

\section{Effect of mass flux}

The approximately constant supply rate delivered by our hopper system with 
a given aperture (Fig. 3a) allowed us to investigate the effect of mass flux on flow behaviour. This is illustrated in Fig. 6 using non-fluidized, aerated and fluidized flows of $15 \mathrm{~kg}$ total mass at fluxes of $0.8,1.8$ and $5 \mathrm{~kg} \mathrm{~s}^{-1}$. Increasing mass flux increased both the flow front velocity and runout distance in all cases, with phase 2 and phase 3 flows responding differently to mass flux (Fig. 6d). Plotting of phase 2, front propagation velocity against mass flux up to $5 \mathrm{~kg} \mathrm{~s}^{-1}$ shows a square-root relationship, perhaps related to the similar power-law dependence of particle concentration as a function of mass flux (see section 2.1). Higher mass fluxes are excluded from these analyses due to their very short duration, resulting in low confidence in both the identification of flow phase transitions and measurement of average velocities. However, tentative observations in the order of $3-4 \mathrm{~m} \mathrm{~s}^{-1}$ for phase 2 front speed in an aerated flow with a $65 \mathrm{~kg} \mathrm{~s}^{-1}$ mass flux are in line with these measurements and related conclusions at a mass flux $<5 \mathrm{~kg} \mathrm{~s}^{-1}$ since the fit curve for $0.5 U_{m f}$ suggests $3.5 \mathrm{~m} \mathrm{~s}^{-1}$ at $65 \mathrm{~kg} \mathrm{~s}^{-1}$. Front velocities of phase 3 propagation have a linear relationship of slope of 3.0 for both non-fluidized and aerated flows.

\section{Fig. 6}

Flow front propagation for various mass fluxes, using a $15 \mathrm{~kg}$ supply which is a non-fluidized (hence the deposit growth occurs largely as a granular wedge at the angle of repose), $\mathbf{b}$ aerated at $0.5 U_{m f}$ and $\mathbf{c}$ fluidized at $1 U_{m f}$. The dotted line represents phase 1 (where present), the heavy line represents phase 2 and the fine line represents phase 3 (where present). Lines end when all flow has ceased $\left(t_{\text {stop }}\right)$, or, in the fluidized $\left(U=U_{m f}\right)$ case, when the flow exits the video frame. It should be noted that in the $5 \mathrm{~kg} \mathrm{~s}^{-1}$ non-fluidized experiment (red line in (a)) the initial phase 1 deposit forms a front which is not over-ridden by phase 2 , but which is eventually over-ridden by phase 3 at $\sim 2.3$ s. Phase 3 propagation between channel entry and overriding the distal extent of phase 2 is not plotted. d Average front speeds calculated for phases 2 (filled) and 3 (open) in experiments using low mass fluxes from $0.8-5 \mathrm{~kg} \mathrm{~s}^{-1}$, to illustrate that in phase 2 the velocities respond to an inverse quadratic of mass flux while in phase 3 front progradation has a linear relationship with mass flux. e Runout distances for different mass fluxes $\left(0.8-65 \mathrm{~kg} \mathrm{~s}^{-1}\right)$ in non-fluidized and aerated conditions. Larger mass fluxes correlate with a longer runout, with this effect further increased when aeration is present 

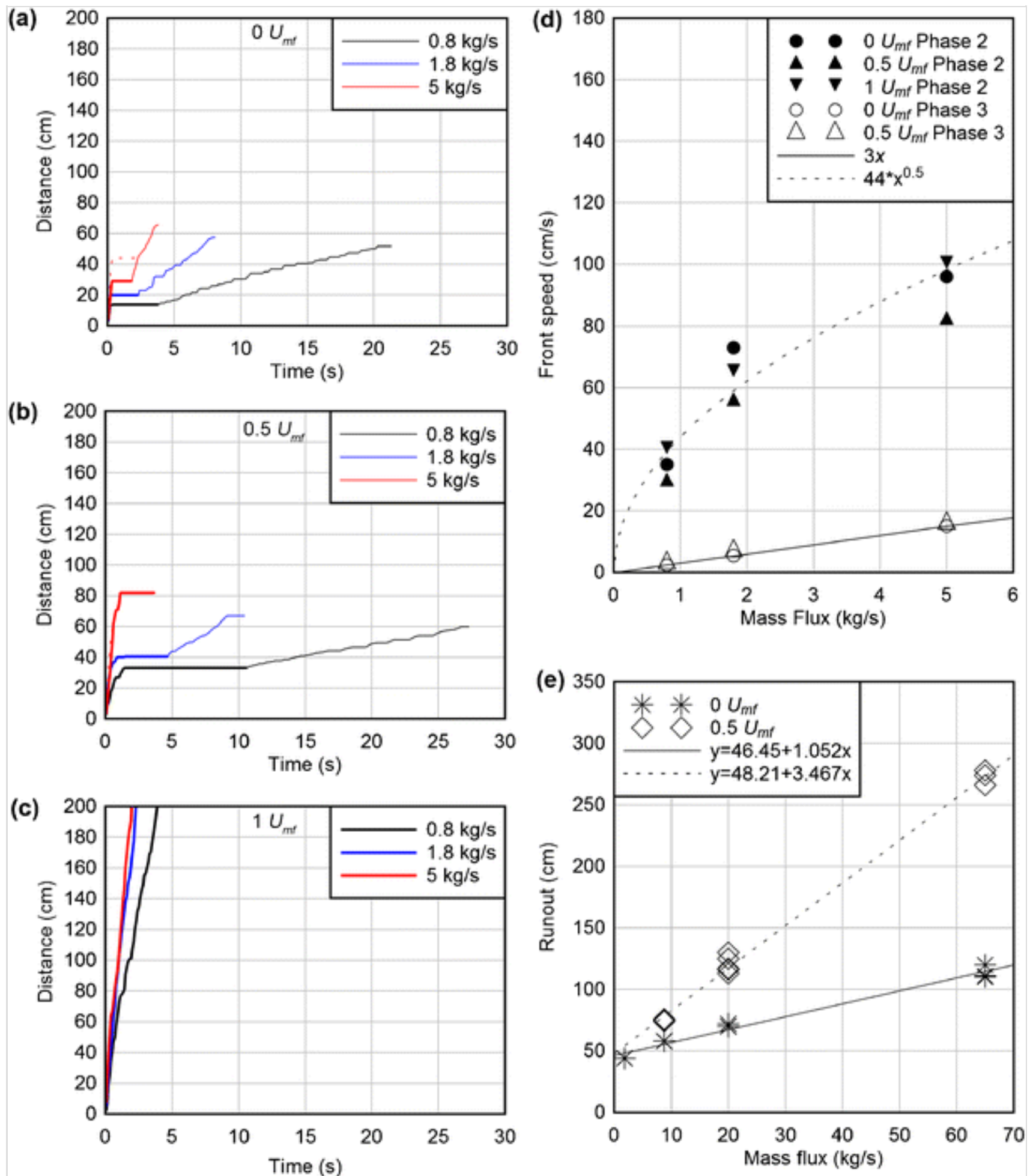

Figure 6e shows the results of a wider set of experiments using a range of mass fluxes between 0.8 and $65 \mathrm{~kg} \mathrm{~s}^{-1}$, and both non-fluidized and aerated conditions. The data demonstrate that flow runout increased linearly with mass flux, with the effect amplified when the flow was aerated, which is an important result of our study. The intercept of the lines on the vertical axis is the lowest possible runout for a charge of that mass (i.e. a static granular wedge at angle of rest).

\section{Effect of fluidization state}


The fluidization state had a variable effect on flow front velocity and on flow runout. At a given mass and mass flux, non-fluidized, aerated and fluidized flows had similar phase 2 frontal velocities (Fig. 7d). Non-fluidized flows formed angle-of-rest wedges; aeration increased the runout of the flow, resulting in a lower-angle wedge with a lower mean thickness to length ratio (Figs. 5b and 6e).

\section{Fig. 7}

Flow front position versus time for non-fluidized $\left(0 U_{m f}\right)$, aerated $\left(0.5 U_{m f}\right)$ and fluidized $\left(\begin{array}{ll}1 & U_{m f}\end{array}\right)$ experiments, using a $15 \mathrm{~kg}$ charge supplied at $5 \mathrm{~kg} \mathrm{~s}^{-1}$. Dotted lines indicate the phase 1 flow, heavy lines phase 2 and fine lines phase 3 (where present). Lines for the non-fluidized and aerated experiments end when the flow has come to a complete rest $\left(t_{\text {stop }}\right)$ and for the fluidized experiment when the flow exits the flume. The non-fluidized phase 3 flow over-runs its phase 2 deposit front at $1.8 \mathrm{~s}$, and its phase 1 deposit after $2.2 \mathrm{~s}$, at which point the non-fluidized phase 3 flow progrades steadily until achieving a final runout $(66 \mathrm{~cm})$ only slightly shorter than that of an aerated flow $(77.5 \mathrm{~cm})$. Aerated conditions produce a more mobile phase 1 and phase 2 flows than non-fluidized conditions, with the initial deposit front from an aerated flow achieving twice the runout of non-fluidized flow after $0.5 \mathrm{~s}$ and almost three times the runout after $1 \mathrm{~s}$. Fluidized flows decelerate gradually along the length of the flume from over $1 \mathrm{~m} \mathrm{~s}^{-1}$ to approximately $0.5 \mathrm{~m} \mathrm{~s}^{-1}$ as the material exits after $4.5 \mathrm{~s}$

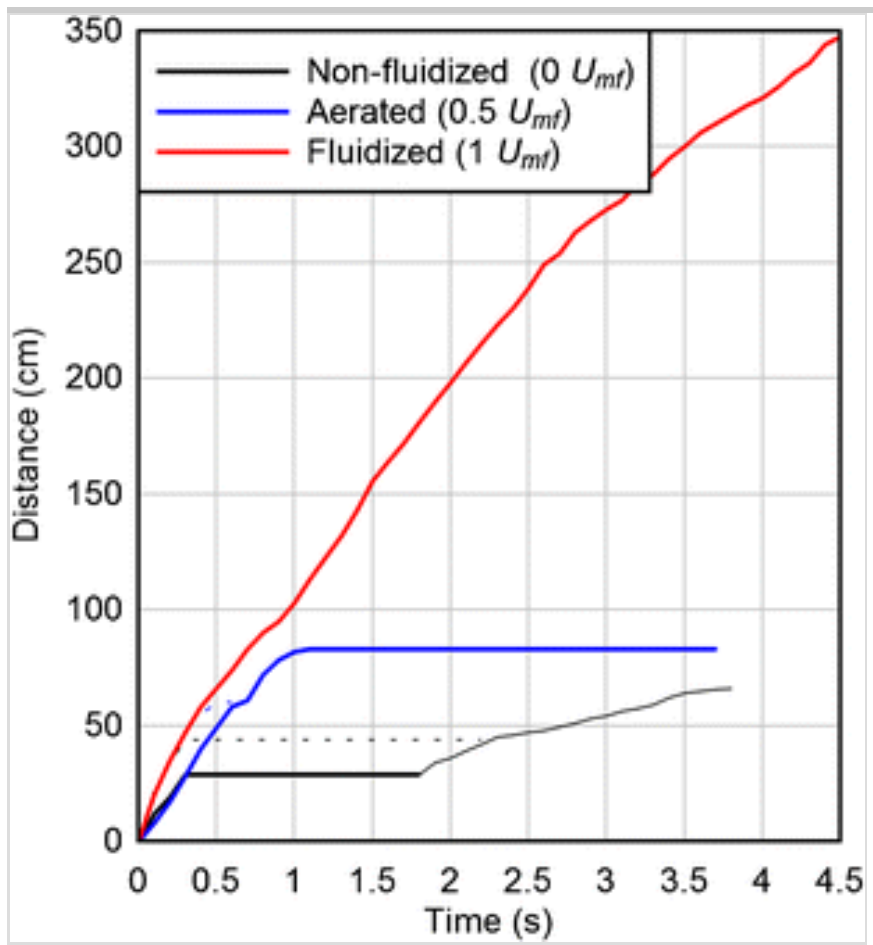




\section{Discussion}

\section{Relative significance of variables}

The effects of each of the three variables (mass, mass flux and fluidization state) on the dense flow velocity and runout are now summarized and discussed.

\section{Velocity}

Phase 2 front velocity of the non-fluidized $(U=0)$, aerated $\left(U=0.5 U_{m f}\right)$ and fluidized $\left(U=1.0 U_{m f}\right)$ flows increased with mass flux according to a square-root relationship for mass fluxes up to at least $5 \mathrm{~kg} \mathrm{~s}^{-1}$ (Fig. 6d), but was rather insensitive to either total particle mass (Fig. 5a) or fluidization state (Figs. 6d and 7). This differs from the phase 3 whose velocity followed a linear relationship with the mass flux in both the non-fluidized and aerated flows, with flows of larger mass simply lasting longer due to the longer supply time. The fundamental difference between these 2 phases is that phase 2 represents the movement of a single flow pulse, while phase 3 is dependant entirely on the rate at which subsequent flow pulses over-run the deposits of earlier pulses. Preexisting deposit surfaces are uneven and unconsolidated, and therefore act to dissipate energy from the over-riding flow, leading to generally reduced runout, except where the slope angle becomes sufficient to add a compensating acceleration.

\section{Flow runout}

The runout of the non-fluidized $(U=0)$ and aerated $\left(U=0.5 U_{m f}\right)$ flows with initial particle concentration up to $\sim 45 \%$ (at $65 \mathrm{~kg} \mathrm{~s}^{-1}$ ) increased linearly with mass flux (Fig. 6e). Increasing mass flux from 0.8 to $65 \mathrm{~kg} \mathrm{~s}^{-1}$ caused a trebling of runout in non-fluidized flows, while having a nearly sixfold effect on the runout of aerated currents (Fig. 6e). Runout also increased with the total mass (Fig. 5b) and with the degree of fluidization (Fig. 7). The runout of fully fluidized flow $(\mathrm{U}=\mathrm{Umf})$ exceeded the $350 \mathrm{~cm}$ length of the flume.

Owing to the characteristics of the hopper particle-feed system, changing the mass flux also resulted in a change of the particle concentration in the collapsing granular mass. Lower mass fluxes were associated with lower initial concentrations so that the granular material had to first density (by gas expulsion) prior to flow generation. Further experiments are required to 
separate the effects of mass flux and initial concentration on flow behaviour. However, it is interesting to note that runout of non-fluidized and aerated flows correlates linearly with mass flux up to at least $65 \mathrm{~kg} \mathrm{~s}^{-1}$. This suggests that the initial particle concentration was unimportant in governing flow behaviour, as dense flows rapidly formed $(<0.1 \mathrm{~s}$ after impingement) even in the most dilute supply conditions and that mass flux was the major controlling variable.

\section{Behaviours of sustained versus transient laboratory flows}

Our experiments serve to highlight some significant difference between transient, dam-break flows (e.g. Roche et al. 2004, 2008; Girolami et al. 2008 ) and sustained granular flows presented here. First, $t_{\text {supply }}$ in sustained flows is longer that $t_{\text {limit }}$, in contrast to dam-break flows, so that particles continue to be supplied to the flow system after the maximum runout distance has been reached. Second, in the dam-break case, almost the entire particle volume is mobilised at once, with the flow steadily thinning as it propagates and deposits. The final deposit thickness is less than or equal to the flow thickness. This is in contrast to the sustained flow case, in which the dense flow pulses, caused by high-frequency fluctuations of the source supply, accumulated to form a final deposit that could be orders of magnitude thicker than the flow.

Another feature of our sustained experimental flows is that the series of pulses formed the deposit through a series of waxing-waning cycles. This contrasts with dam-break experiments in which there is a single, rapid cycle of waxing, then waning, flow (Girolami et al. 2008; Roche et al. 2004; Roche 2012). This unsteadiness in the sustained flows generated deposits with complex internal architectures characterized by multiple, stacked progradational and retrogradational surfaces. While these conditions are interesting from a field perspective, as discussed below, a challenge in future experiments will be to employ source supply conditions that do not generate such strong flow unsteadiness, in order to properly evaluate the influence of other parameters.

Finally, the frontal velocity and runout of dam-break flows are controlled by the initial bed height and the fluidization state (Roche et al. 2008). In sustained flows, an additional factor is the mass flux (and through it the particle supply duration), which has an additional strong effect not relevant 
in transient flows. Though higher bed height in dam-break experiments causes higher flow velocity and hence mass flux, we recall that our sustained flows were generated from a source at constant height, demonstrating that the mass flux also controls flow emplacement.

\section{Implications for dense pyroclastic density currents}

While fluidized granular flows generated in dam-break configurations provide insight into the dynamics of either a single pyroclastic flow unit during a sustained eruption or a transient flows from lava dome collapse or the fallback of vulcanian columns, our present experimental system offers a way of investigating pyroclastic flows and ignimbrites formed by sustained fountain collapse. Moreover, sustaining high pore pressure by injection of gas during flow allows us to mimic experimentally long-lived pore pressure due to sustained external and/or internal gas sources, particle hindered settling and slow pressure diffusion characteristic of natural pyroclastic flows, which could not be achieved in experiments with initial fluidization at source only. Sustained high pore pressure enables even thin (mm-scale) experimental flows to propagate for several metres. Moreover, the apparatus allows even relatively thin flows (millimetres to centimetres in these experiments) to progressively accrete a deposit, the final thickness of which is much greater than the flow pulses themselves.

Although our results are very preliminary, it is worth noting some possible applications to the transport and deposition behaviour of high-concentration PDCs (i.e. pyroclastic flows) and the formation of thick ignimbrites. First, the experiments show that sustained aerated flows are emplaced as three phases. In phase 1, initial impact of the collapsing particles (crudely analogous to a collapsing eruption column) may generate high gas pressures and a 'spray' of particles that shoots ahead of the main flow, accompanied by a dilute cloud of particles. This precursor flow lays down a very thin deposit, typically displaying a highly asymmetric and/or lobate front, which is then over-run by the main phase 2 flow. Although our experiments in no way scale to the natural system in this respect, regarding particularly turbulence, we speculate that this kind of phenomenon might account in some cases for the 'ground surge deposits' commonly observed at the base of ignimbrites (Sparks et al. 1973; Wilson 1980; Wright et al. 1980; Valentine et al. 1989; Fisher et al. 1993; Dellino and La Volpe 2000). The experiments presented here represent the dense end of the PDC spectrum while natural 
flows are likely to encompass a broader range of characteristics, including the turbulent dilute end member (e.g. Andrews and Manga 2012). The spray observed in our experiments has some similarities with the initial blast wave generated by collapsing eruption columns in the numerical models of Wohletz et al. (1984). Also, the deposit resembles that of the so-called 'surge' observed by Roche et al. (2011) in their experiments, as high pore pressure at base of a fluidized granular column is suddenly released, being very thin and emplaced rapidly and asymmetrically ahead of the larger dense flow.

The second feature of our experiments is that the main phase 2 dense flow forms readily at the impingement surface even with collapsing material concentrations as low as $\sim 3-4$ vol.\%. This is an important result of our study. The phase 2 flow travels out to a distal limit, determined by the mass flux, total mass and particle fluidization state. Phase 3 sees the deposit aggrade vertically to a final thickness much greater than that of the phase-2 flow. During the extended deposition of phase 3 material, the distal limit may or may not advance further, essentially because the pulses have lower velocity than the main phase 2 flow. We infer from this that sustained pyroclastic flows may reach a distal limit relatively early in their emplacement, after which the remainder of the deposit will vertically aggrade through accumulation of pulses to form thick ignimbrite. The exact behaviour in nature would, of course, depend on temporal variations in the source mass flux, the fluidization state of the flow and/or the ground slope. Nevertheless, the experimental flows support the interpretation that thick ignimbrites can aggrade progressively from a sustained supply of thin, flowing granular material, without the necessity of thick individual flow units (Sparks 1976; Wright and Walker 1981; Hayashi and Self 1992; Palladino and Valentine 1995; Calder et al. 2000; Branney and Kokelaar 2002; Wilson and Hildreth 2003; Brown and Branney 2004b; Fierstein and Wilson 2005).

Third, although the unsteadiness in our experimental flows was inherent to the feeder mechanism, it is likely that natural pyroclastic flows are similarly unsteady on a short timescale (even if they are quasi-steady on a longer timescale). Unsteadiness leads to temporal and spatial variations of thickness, velocity and momentum in the flow system. In addition to the high-frequent unsteadiness, the experiments show a waxing (as first material is provided) and then waning (as there is no more material from the hopper) 
phase, as is thought to occur in some cases of ignimbrite emplacement (Williams et al. 2014). The complex internal architectures of the experimental deposits (Fig. 4), including stacked progradational and retrogradational surfaces, resemble those of some natural ignimbrites (e.g. Branney and Kokelaar 2002; Wilson and Hildreth 2003; Brown and Branney 2004a; Brown et al. 2007). It is possible such features are present in many deposits, but are masked by uniform grain size characteristics (Rowley et al. 2011). The response of the later stages of the experimental flows to topography formed by earlier phases is entirely fitting with PDC behaviour, which is seen to have strong responses to even relatively minor changes in topography (e.g. Giordano 1998; Pittari et al. 2006; Doronzo and Dellino 2014).

The ability of the experimental flows to aggrade deposits that are much thicker than the flows themselves is notably similar to the aggradation mechanism invoked in a number of ignimbrite deposits (e.g. (Branney and Kokelaar 1997; Cas et al. 2011). These experimental dense flows were fed purely from the proximal end of the flume, with material ranging from highly dilute ( $\sim 3-4$ vol.\%) to highly concentrated ( $\sim 45$ vol.\%).

\section{Conclusions}

Our experiments using granular flows on a horizontal slope fed by a continuous supply of collapsing material onto an impingement surface enable the investigation of some of the behaviours of sustained PDCs. They consider non-fluidized flows as well as aerated and fully fluidized flows generated by continuous gas supply to their base, which permits the simulation of long-lived high pore pressure that favours propagation. Nonfluidized and aerated flows propagate in three distinct but overlapping phases; an initial fast dilute spray (phase 1), a subsequent slower dense unsteady flow which may over-ride the phase 1 deposit (phase 2), and finally sustained aggradation through unsteady dense flow pulses (phase 3). An important result of our study is that dense flows at almost maximum particle concentration are generated as particles accumulate at the impingement surface, even when the particle concentration at source is of a few percent.

Mass flux has a strong control on flow behaviour, with an inverse-quadratic relationship to phase 2 flow front velocity in the ranges observed, becoming a linear control on the propagation velocity of the front of the deposit during phase 3 , formed by accumulation of pulses in both non-fluidized and aerated 
flows. A linear dependence is observed in the runout distance of nonfluidized and aerated flows for a range of mass fluxes up to $65 \mathrm{~kg} \mathrm{~s}^{-1}$, corresponding to a particle concentration of $\sim 45 \%$. Fluidized flows remain mobile, with essentially infinite runouts. As in dam-break experiments, charge mass is of secondary importance in the control of flow speed or runout, whatever the degree of fluidization of the flows.

The experiments demonstrate the ability of sustained granular flows to aggrade deposits many times thicker than the primary phase- 2 flow and the subsequent phase-3 pulses, with complex internal architectures typical of many ignimbrites produced by temporal and spatial variation in flow properties.

\section{Acknowledgments}

PR was supported by a Université Blaise Pascal postdoctoral fellowship, with experimental work funded by a grant from the volcanology group of the Laboratoire Magmas et Volcans. This is Laboratory of Excellence ClerVolc (ANR-10-LABX-0006) contribution number 106. We thank the reviewers B. Andrews and C. Wilson, whose comments and suggestions significantly improved this manuscript.

\section{Electronic supplementary material}

Below is the link to the electronic supplementary material.

Online Resource 1 (MPG 74368 kb)

\section{References}

Andrews B, Manga M (2011) Effects of topography on pyroclastic density current runout and formation of coignimbrites. Geology 39(12):1099-1103. doi:1010.1130/G32226.32221

Andrews BJ, Manga M (2012) Experimental study of turbulence, sedimentation, and coignimbrite mass partitioning in dilute pyroclastic density currents. J Volcanol Geotherm Res 225:30-44. doi:

$10.1016 / \mathrm{j}$.jvolgeores.2012.02.011 
Bareschino P, Lirer L, Marzocchella A, Petrosino P, Salatino P (2008) Self-fluidization of subaerial rapid granular flows. Powder Technol 182:323-333. doi: 10.1016/j.powtec.2007.12.010

Bernal J, Mason J (1960) Packing of spheres: Coordination of randomly packed spheres. Nature 188:910-911. doi: 10.1038/188910a0

Boudet J, Amarouchene Y, Bonnier B, Kellay H (2007) The granular jump. J Fluid Mech 572:413-432. doi: 10.1017/S002211200600365X

Branney MJ, Kokelaar P (1997) Giant bed from a sustained catastrophic density current flowing over topography: Acatlan ignimbrite, Mexico. Geology 25:115-118. doi: 10.1130/00917613(1997)025<0115:GBFASC $>2.3 . \mathrm{CO} ; 2$

Branney MJ, Kokelaar BP (2002) Pyroclastic density currents and the sedimentation of ignimbrites. Geol Soc London Memoir, 27 $\mathrm{AQ} 2$

Brown RJ, Branney MJ (2004a) Bypassing and diachronous deposition from density currents: Evidence from a giant regressive bed form in the Poris ignimbrite, Tenerife, Canary Islands. Geology 32:445-448. doi: $10.1130 / \mathrm{G} 20188.1$

Brown RJ, Branney MJ (2004b) Event-stratigraphy of a caldera-forming ignimbrite eruption on Tenerife: the $273 \mathrm{ka}$ Poris formation. Bull Volcanol 66:392-416. doi: 10.1007/s00445-003-0321-y

Brown RJ, Kokelaar B, Branney MJ (2007) Widespread transport of pyroclastic density currents from a large silicic tuff ring: the Glaramara tuff, Scafell caldera, English Lake District, UK. Sedimentology 54:11631190. doi: 10.1111/j.1365-3091.2007.00877.x

Calder E, Sparks R, Gardeweg M (2000) Erosion, transport and segregation of pumice and lithic clasts in pyroclastic flows inferred from ignimbrite at Lascar Volcano, Chile. J Volcanol Geotherm Res 104:201235. doi: 10.1016/S0377-0273(00)00207-9

Carlevaro CM, Pugnaloni LA (2012) Arches and contact forces in a 
granular pile. Eur Phys J E 35:1-7. doi: 10.1140/epje/i2012-12044-7

Cas RA, Wright HM, Folkes CB, Lesti C, Porreca M, Giordano G, Viramonte JG (2011) The flow dynamics of an extremely large volume pyroclastic flow, the 2.08-Ma Cerro Galán Ignimbrite, NW Argentina, and comparison with other flow types. Bull Volcanol 73:1583-1609. doi: 10.1007/s00445-011-0564-y

Chédeville C, Roche O (2014) Autofluidization of pyroclastic flows propagating on rough substrates as shown by laboratory experiments. $\mathrm{J}$ Geophys Res 119:1764-1776. doi: 10.1002/2013JB010554

Dellino P, La Volpe L (2000) Structures and grain size distribution in surge deposits as a tool for modelling the dynamics of dilute pyroclastic density currents at La Fossa di Vulcano (Aeolian Islands, Italy). J Volcanol Geotherm Res 96:57-78. doi: 10.1016/S0377-0273(99)00140-7

Dellino P, Zimanowski B, Büttner R, La Volpe L, Mele D, Sulpizio R (2007) Large-scale experiments on the mechanics of pyroclastic flows: Design, engineering, and first results. J Geophys Res 112:B04202. doi: 10.1029/2006JB004313

Doronzo DM, Dellino P (2014) Pyroclastic density currents and local topography as seen with the conveyer model. J Volcanol Geotherm Res 278:25-39. doi: 10.1016/j.jvolgeores.2014.03.012

Druitt TH (1998) Pyroclastic density currents. In: Gilbert JS, Sparks RSJ (eds) The physics of explosive volcanic eruptions. Special Publications 145, London, pp 145-182

Druitt TH, Bruni G, Lettieri P, Yates JG (2004) The fluidization behaviour of ignimbrite at high temperature and with mechanical agitation. Geophys Res Lett 31, L02604. doi: 10.1029/2003GL018593

Druitt TH, Avard G, Bruni G et al (2007) Gas retention in fine-grained pyroclastic flow materials at high temperatures. Bull Volcanol 69:881901. doi: $10.1007 / \mathrm{s} 00445-007-0116-7$

Dufek J, Bergantz G (2007a) Suspended load and bed-load transport of 
particle-laden gravity currents: the role of particle-bed interaction. Theor Comp Fluid Dyn 21:119-145. doi: 10.1007/s00162-007-0041-6

Dufek J, Bergantz GW (2007b) Dynamics and deposits generated by the Kos Plateau Tuff eruption: Controls of basal particle loss on pyroclastic flow transport. Geochem Geophy Geosy 8:1525-2027

Dufek J, Wexler J, Manga M (2009) Transport capacity of pyroclastic density currents: Experiments and models of substrate-flow interaction. J Geophys Res 114:B11203. doi: 10.1029/2007GC001741

Eames I, Gilbertson M (2000) Aerated granular flow over a horizontal rigid surface. J Fluid Mech 424:169-195. doi:

$10.1017 / \mathrm{S} 0022112000001920$

Esposti-Ongaro T, Barsotti S, Neri A, Salvetti MV (2011) Large-eddy simulation of pyroclastic density currents. In: Salvetti MV, Geurts B, Meyers J, Sagaut P (eds) Quality and reliability of large-eddy simulations II. Springer, Netherlands, pp 161-170. doi: 10.1007/978-94-007-0231$8 \_15$

Fan L-S, Zhu C (2005) Principles of gas-solid flows. Cambridge University Press, USA

Fierstein J, Wilson CJN (2005) Assembling an ignimbrite:

Compositionally-defined flow packages in the 1912 valley of ten thousand smokes ignimbrite, Alaska. Geol Soc Am Bull 117:1094-1107. doi: 10.1130/B25621.1

Fisher RV, Orsi G, Ort M, Heiken G (1993) Mobility of a large-volume pyroclastic flow-Emplacement of the Campanian ignimbrite, Italy. J Volcanol Geotherm Res 56:205-220. doi: 10.1016/0377-0273(93)90017$\mathrm{L}$

Geldart D (1972) The effect of particle size and size distribution on the behaviour of gas-fluidised beds. Powder Technol 6:201-215. doi: 10.1016/0032-5910(72)83014-6

Geldart D (1973) Types of gas fluidization. Powder Technol 7:285-292. 
doi: $10.1016 / 0032-5910(73) 80037-3$

Gilbertson MA, Eames I (2003) The influence of particle size on the flow of fluidised powders. Powder Technol 131:197-205. doi: 10.1016/S00325910(02)00343-1

Gilbertson MA, Jessop DE, Hogg AJ (2008) The effects of gas flow on granular currents. Phil Trans R Soc A 366:2191-2203. doi: $10.1098 /$ rsta.2007.0021

Giordano G (1998) The effect of paleotopography on lithic distribution and facies associations of small volume ignimbrites: the WTT Cupa (Roccamonfina volcano, Italy). J Volcanol Geotherm Res 87:255-273. doi: 10.1016/S0377-0273(98)00096-1

Girolami L, Druitt TH, Roche O, Khrabrykh Z (2008) Propagation and hindered settling of laboratory ash flows. J Geophys Res 113, B02202. doi: 10.1029/2007JB005074

Hayashi J, Self S (1992) A comparison of pyroclastic flow and debris avalanche mobility. J Geophys Res 97:9063-9071. doi:

$10.1029 / 92 J B 00173$

Hoblitt RP (1986) Observations of the eruptions of July 22 and August 7, 1980, at Mount St. Helens, Washington. USGS Professional Paper 1335

Iverson RM, LaHusen RG (1989) Dynamic pore-pressure fluctuations in rapidly shearing granular materials. Science 246:796-799. doi: 10.1126/science.246.4931.796

Loughlin S, Baxter P, Aspinall W et al (2002) Eyewitness accounts of the 25 June 1997 pyroclastic flows and surges at Soufrière Hills Volcano, Montserrat, and implications for disaster mitigation. Geol Soc London Memoirs 21:211-230. doi: 10.1144/GSL.MEM.2002.021.01.10

Lube G, Cronin SJ, Platz T et al (2007) Flow and deposition of pyroclastic granular flows: a type example from the 1975 Ngauruhoe eruption, New Zealand. J Volcano Geotherm Res 161:165-186. doi: 10.1016/j.jvolgeores.2006.12.003 
Middleton GV (1966) Experiments on density and turbidity currents: I. motion of the head. Can J Earth Sci 3:523-546. doi: 10.1139/e66-038

MiDi GDR (2004) On dense granular flows. Eur Phys J E 14:341-365. doi: 10.1140/epje/i2003-10153-0

Nakashima K, Johno Y, Shigematsu T (2009) Free fall characteristics of particle clusters in a vertical pipe. J Phys: Conf Ser 147:012070. doi: $10.1088 / 1742-6596 / 147 / 1 / 012070$

Nezzal A, Large J, Guigon P (1998) Fluidisation behaviour of very cohesive powders under mechanical agitation. In: Fluidization VIII, Proc Eighth Engineering Foundation Conference on Fluidization, May 14-19. Am Inst Chem Eng 77-82

Palladino DM, Valentine GA (1995) Coarse-tail vertical and lateral grading in pyroclastic flow deposits of the Latera Volcanic Complex (Vulsini, central Italy): Origin and implications for flow dynamics. J Volcanol Geotherm Res 69:343-364. doi: 10.1016/0377-0273(95)000364

Pittari A, Cas R, Edgar C, Nichols HJ, Wolff JA, Marti J (2006) The influence of palaeotopography on facies architecture and pyroclastic flow processes of a lithic-rich ignimbrite in a high gradient setting: the Abrigo Ignimbrite, Tenerife, Canary Islands. J Volcanol Geotherm Res 152:273315. doi: 10.1016/j.jvolgeores.2005.10.007

Rhodes MJ (2008) Introduction to particle technology. Wiley, Chichester

Roche O (2012) Depositional processes and gas pore pressure in pyroclastic flows: an experimental perspective. Bull Volcanol 74:18071820. doi: 10.1007/s00445-012-0639-4

Roche O, Gilbertson MA, Phillips JC, Sparks RSJ (2004) Experimental study of gas-fluidized granular flows with implications for pyroclastic flow emplacement. J Geophys Res 109:B10201. doi:

10.1029/2003JB002916

Roche O, Gilbertson MA, Phillips JC, Sparks RSJ (2006) The influence 
of particle size on the flow of initially fluidised powders. Powder Technol 166:167-174. doi: 10.1016/j.powtec.2006.05.010

Roche O, Montserrat S, Niño Y, Tamburrino A (2008) Experimental observations of water-like behavior of initially fluidized, unsteady dense granular flows and their relevance for the propagation of pyroclastic flows. J Geophys Res 113:B12203. doi: 10.1029/2008JB005664

Roche O, Montserrat S, Niño Y, Tamburrino A (2010) Pore fluid pressure and internal kinematics of gravitational laboratory air-particle flows: Insights into the emplacement dynamics of pyroclastic flows. J Geophys Res 115:B09206. doi: 10.1029/2009JB007133

Roche O, Attali M, Mangeney A, Lucas A (2011) On the run-out distance of geophysical gravitational flows: Insight from fluidized granular collapse experiments. Earth Planet Sci Lett 311:375-385. doi:

10.1016/j.epsl.2011.09.023

Rowley PJ, Kokelaar P, Menzies M, Waltham D (2011) Shear-derived mixing in dense granular flows. J of Sed Res 81:874-884. doi: $10.2110 /$ jsr.2011.72

Savage SB, Oger L (2013) Airslide flows, part 1-experiments, review and extension. Chem Eng Sci 91:35-43. doi: 10.1016/j.ces.2012.12.043

Schellart W (2000) Shear test results for cohesion and friction coefficients for different granular materials: Scaling implications for their usage in analogue modelling. Tectonophysics 324:1-16. doi: 10.1016/S0040-1951(00)00111-6

Schmincke H-U, Fisher RV, Waters AC (1973) Antidune and chute and pool structures in the base surge deposits of the Laacher See area, Germany. Sedimentology 20:553-574. doi: 10.1111/j.13653091.1973.tb01632.x

Simpson JE (1999) Gravity currents: In the environment and the laboratory. Cambridge University Press, Cambridge

Song C, Wang P, Makse HA (2008) A phase diagram for jammed matter. 
Nature 453:629-632. doi: 10.1038/nature06981

Sparks RSJ (1976) Grain size variations in ignimbrites and implications for the transport of pyroclastic flows. Sedimentology 23:147-188. doi: 10.1111/j.1365-3091.1976.tb00045.x

Sparks RSJ, Self S, Walker GPL (1973) Products of ignimbrite eruptions. Geology 1:115-118. doi: 10.1130/0091-

7613(1973) $1<115:$ POIE $>2.0 . C O ; 2$

Valentine GA, Buesch DC, Fisher RV (1989) Basal layered deposits of the Peach Springs Tuff, northwestern Arizona, USA. Bull Volcanol 51:395-414. doi: 10.1007/BF01078808

Walton OR, Braun RL (1986) Viscosity, granular-temperature, and stress calculations for shearing assemblies of inelastic, frictional disks. J Rheol 30:949-980. doi: 10.1122/1.549893

Williams R, Branney MJ, Barry TL (2014) Temporal and spatial evolution of a waxing then waning catastrophic density current revealed by chemical mapping. Geology 42:107-110, doi:110.1130/G34830.34831

Wilson CJN (1980) The role of fluidization in the emplacement of pyroclastic flows: an experimental approach. J Volcanol Geotherm Res 8:231-249. doi: 10.1016/0377-0273(80)90106-7

Wilson CJN, Hildreth W (2003) Assembling an ignimbrite: Mechanical and thermal building blocks in the Bishop Tuff, California. J Geol 111:653-670. doi: 10.1086/378335

Wohletz KH, McGetchin T, Sandford M II, Jones E (1984) Hydrodynamic aspects of caldera-forming eruptions: Numerical models. J Geophys Res 89:8269-8285. doi: 10.1029/JB089iB10p08269

Wright JV, Walker GP (1981) Eruption, transport and deposition of ignimbrite: a case study from Mexico. J Volcanol Geotherm Res 9:111131. doi: 10.1016/0377-0273(81)90001-9

Wright JV, Smith AL, Self S (1980) A working terminology of pyroclastic 
deposits. J Volcanol Geotherm Res 8:315-336. doi: 10.1016/03770273(80)90111-0 